\title{
STUDY OF THE EFFECTS OF SILVER NITRATE IN TREATMENT OF ALLERGIC RHINITIS
}

\author{
Ramya Sablur Narayan ${ }^{1}$
}

${ }^{1}$ Assistant Professor, Department of Otolaryngology, ESIC-MC-PGIMSR, Bengaluru, Karnataka.

ABSTRACT

\section{BACKGROUND}

Rhinitis is defined as the presence of at least one of the following: congestion, rhinorrhoea, sneezing, nasal itching and nasal obstruction. Other reported symptoms include throat clearing, headaches, facial pain, ear pain, itchy throat and palate, snoring and sleep disturbances. Risk factors include an atopic family history, IgE levels above $100 \mathrm{IU} / \mathrm{mL}$ before the age of six years, higher socioeconomic status and positive epicutaneous allergen testing.

The aim of this study is to evaluate the efficacy of application of topical 15\% silver nitrate solution for treatment of allergic rhinitis.

\section{MATERIALS AND METHODS}

A descriptive study of total 100 patients clinically diagnosed with allergic rhinitis presenting with sneezing, rhin orrhoea and nasal obstruction were included in the study. $15 \%$ silver nitrate solution was used to cauterize the anterior part of both inferior turbinates and the corresponding parts of the nasal septum over an area of $1 \mathrm{sq}$. cm. This was repeated for five weeks at weekly interval.

Settings and Design- The study was conducted for a period of one year from Nov 2005 to Nov 2006 at Father Muller Medical College Hospital, Mangalore.

\section{RESULTS}

Out of 100 cases, $55 \%$ were females and $45 \%$ were males. Out of the 100 patients, 89 were male and 16 were female. Their age ranged from 18 - 59 years. We found 73 out of 93 cases improved after five applications of $15 \%$ silver nitrate, giving a successful rate of $78.49 \%$

\section{CONCLUSION}

Application of silver nitrate to inferior turbinates for nasal obstruction is effective in upto $78.49 \%$ cases. It is well tolerated, carried under local anaesthesia, is cheap and can be carried out at any outpatient clinic with minor side effects.

\section{KEYWORDS}

Allergic Rhinitis, Silver Nitrate.

HOW TO CITE THIS ARTICLE: Narayan RS. Study of the effects of silver nitrate in treatment of allergic rhinitis. J. Evolution Med. Dent. Sci. 2018;7(13):1644-1647, DOI: 10.14260/jemds/2018/371

\section{BACKGROUND}

Rhinitis is defined as the presence of at least one of the following: congestion, rhinorrhoea, sneezing, nasal itching and nasal obstruction.1,2 Other reported symptoms include throat clearing, headaches, facial pain, ear pain, itchy throat and palate, snoring and sleep disturbances. ${ }^{3,4}$ Risk factors include an atopic family history, IgE levels above $100 \mathrm{IU} / \mathrm{mL}$ before the age of six years, higher socioeconomic status and positive epicutaneous allergen testing. ${ }^{1}$ Since allergic rhinitis is induced by specific allergens, it makes sense that avoiding those triggers would be an effective treatment. However, this is not always possible as in the case of pollens and for those with mixed allergic and non-allergic rhinitis, avoidance will not completely alleviate their symptoms. All rhinitis symptoms, except for obstruction can be alleviated by H1antihistamines. Topical $\mathrm{H} 1$ antihistamines (Azelastine, olopatadine) provided faster onset of action (less than 15 minutes) and similar to greater efficacy compared to oral

'Financial or Other Competing Interest': None.

Submission 06-02-2018, Peer Review 08-03-2018,

Acceptance 14-03-2018, Published 26-03-2018.

Corresponding Author:

Ramya Sablur Narayan,

Department of Otolaryngology,

ESIC-MC-PGIMSR, Rajajinagar,

Bengaluru, Karnataka.

E-mail: rajukp74@gmail.com

DOI: $10.14260 /$ jemds $/ 2018 / 371$

\section{(c) $(1) \ominus$}

preparations in regard to rhinitis and conjunctivitis. In addition to oral H1-antihistamines, intranasal corticosteroids are the mainstay of treatment. They are the most effective medications for controlling all rhinitis symptoms. Systemic corticosteroids should be considered a last resort treatment option, but they may be necessary for severe or intractable symptoms. Intranasal formulations of cromolyn and nedocromil have been used to treat allergic rhinitis, but are less effective than topical corticosteroids. Subcutaneous immunotherapy (SCIT) has been shown to be effective in treating allergic rhinitis in patients with identifiable IgE mediated symptom triggers. It has some advantages over the above mentioned treatments.

This study was undertaken to evaluate the efficacy of application of topical $15 \%$ silver nitrate solution for treatment of allergic rhinitis. This study describes the technique, uses and results obtained following the application of $15 \%$ silver nitrate on the inferior turbinate in patients with allergic rhinitis.

\section{MATERIALS AND METHODS}

This descriptive study was conducted for a period of one year from Nov 2005 to Nov 2006 at Father Muller Hospital, Mangalore. A total of 100 patients clinically diagnosed with allergic rhinitis presenting with sneezing, rhinorrhoea and nasal obstruction were included in the study.

Before commencing the treatment, a detailed history was elicited from the patients, particularly in relation to the 
duration of disease, previous medication and extent of relief with previous methods of treatment. A meticulous general physical examination was done and this was followed by systemic examination. A thorough ear, nose, throat and head and neck examination was conducted and all the findings were recorded in the proforma. Absolute eosinophil count was done for all the patients included in the study. After the definitive diagnosis, the nose was sprayed with $10 \%$ xylocaine. No premedication was used. After five minutes, a swab stick dipped in $15 \%$ silver nitrate solution was used to cauterize the anterior part of both inferior turbinates and the corresponding parts of the nasal septum over an area of one sq. $\mathrm{cm}$. This was repeated for five weeks at weekly interval. No other treatment was allowed during this period, except a single tablet of cetirizine on the day of application to alleviate the nasal irritation.

\section{Statistical Analysis}

The demographic data, frequency and percentages were calculated with bar diagrams and pie chart. Statistical software- Epi-Info 7.0 was used for computations.

\section{RESULTS}

All the patients presented with sneezing and nasal discharge. 90 out of 100 patients had nasal obstruction. Nasal irritation and headache were present in $83 \%$ and $23 \%$ respectively. Ocular symptoms were present in $10 \%$ of cases. The followup period varied from one to six months.

Out of 100 cases, $55 \%$ were females and $45 \%$ were males. The maximum subjects were in the age group of 18 - 29 years $46(46 \%)$ followed by 40 - 59 years 30 (30\%), (Figure 1). Sneezing was of the duration of $2-5$ years in $53 \%, 6-10$ yrs. in 34\%, 6 months to 1 year in 7\%, 11 - 15 years in 3\% and less than 6 months in 3\% of cases. Nasal discharge was of the duration of 2 - 5 years is 53\%, 6 - 10 yrs. in 34\%, 6 months - 1 year in 7\%, 11 - 15 years in 3\% and less than 6 months in $3 \%$ of cases. Nasal obstruction was of duration 2 - 5 years in $45 \%$ of cases, 6 months - 1 year in 25\%, less than 6 months in $12 \%, 6-10$ yrs. in $8 \%$ of cases, (Table I). All patients presented with sneezing and nasal discharge. Patients who had 30 or more sneezes per day were selected. This was followed by nasal obstruction in $90 \%$ of cases. Nasal irritation was present in $83 \%$ of cases. Headache and ocular symptoms in $23 \%$ and $10 \%$ respectively. Other symptoms like cough, itching and blocking sensation of the ears and wheeze were present in $71 \%$ of cases, (Figure 2). The examination findings of these patients revealed pale and oedematous mucosa was seen in $34 \%$ of cases, watery discharge was seen in $90 \%$ of cases, deviated nasal septum was observed in $51 \%$ of cases. Both infirm turbinate were hypertrophied in $64 \%$ of cases while unilateral hypertrophy was observed in $28 \%$ of cases. In eight cases, no hypertrophy was seen (Figure 3).

The Results of Symptomatic Relief were graded as follows in Case of Sneezes-

- 0 - 5 sneezes per day good.

- 6 - 10 sneezes per day as fair.

- More than 10 sneezes per day as $\&$ poor.
The best relief obtained was from sneezing with good relief in $80 \%$ and fair in $13 \%$ of cases. The treatment with $15 \%$ silver nitrate solution was effective in relieving rhinorrhoea with good relief in 55\% and fair in 38\% of cases. The nasal obstruction had good relief in $61 \%$ cases and fair in $39 \%$. Headache was relieved in $65 \%$ of cases. Ocular symptoms were controlled in $70 \%$ of cases. The other symptoms like wheezing, cough, ear itching and blocking sensation of the ears were fairly relieved in $56 \%$ of cases, (Table 2). Out of 100 patients, 93 of them attended follow-up regularly and 7 of them discontinued (Figure 4). 73 out of 93 cases improved after five applications with $15 \%$ silver nitrate. This gives a successful results of $78.49 \%$. These cases have been followed up for a period ranging from 1 to 6 months (Table 3).

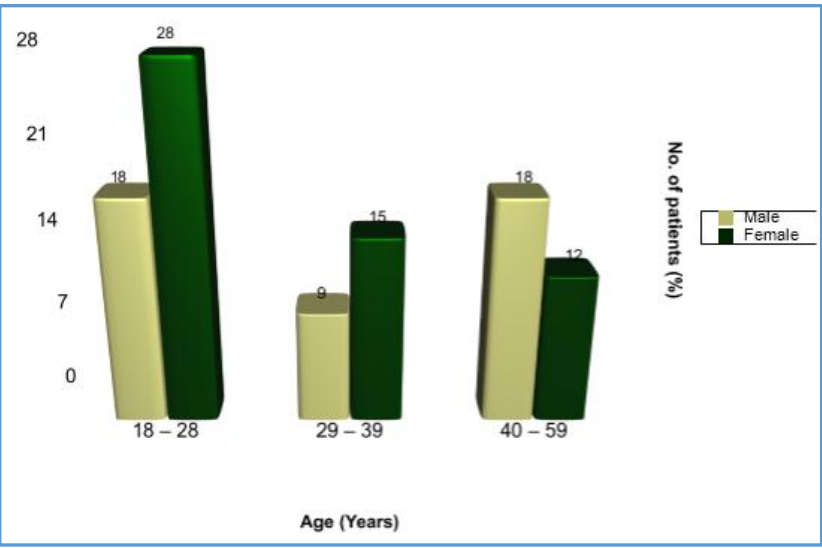

Figure 1. Age and Sex Wise Distribution

\begin{tabular}{|c|c|c|c|c|c|}
\hline Symptoms & $\begin{array}{c}\text { 1 Month - 6 Months } \\
\text { 6 Months }\end{array}$ & $\begin{array}{c}\text { 2 Year } \\
\text { - 1 Year }\end{array}$ & $\begin{array}{c}\text { 6-10 } \\
\text { Years }\end{array}$ & $\begin{array}{c}\text { 11-15 } \\
\text { Years }\end{array}$ \\
\hline Sneezing & 3 & 7 & 53 & 34 & 3 \\
\hline $\begin{array}{c}\text { Nasal } \\
\text { Discharge }\end{array}$ & 3 & 7 & 53 & 34 & 3 \\
\hline $\begin{array}{c}\text { Nasal } \\
\text { Obstruction }\end{array}$ & 12 & 25 & 45 & 8 & - \\
\hline
\end{tabular}

Table 1. Distribution of Patients according to Duration of Main Symptoms

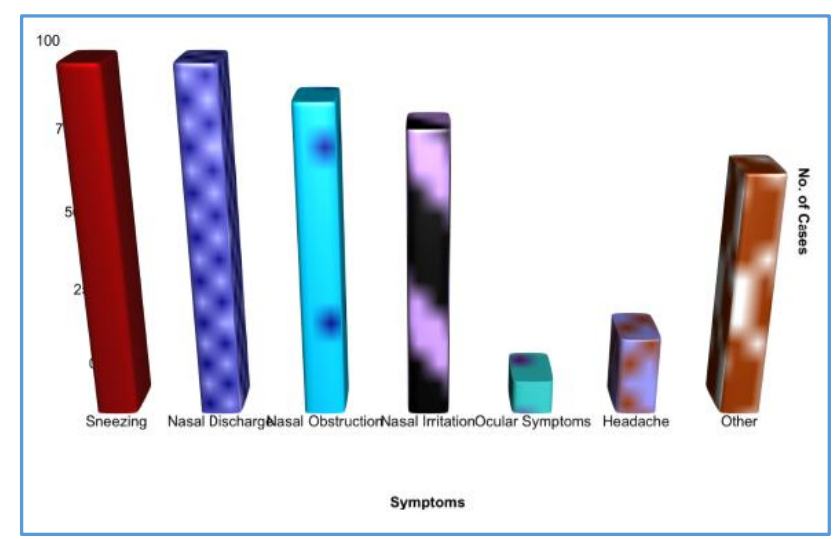

Figure 2. Symptom Wise Analysis of Patients 


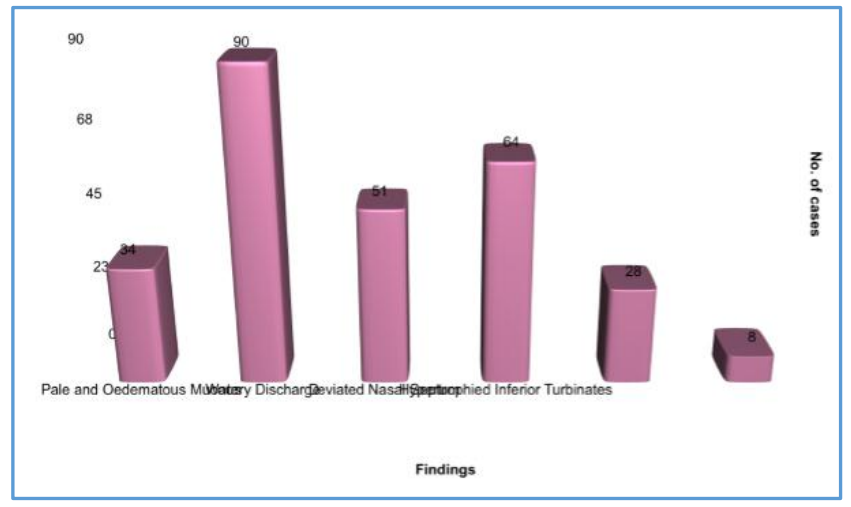

Figure 3. Examination Findings

\begin{tabular}{|c|c|c|c|c|}
\hline Symptoms & No. of Cases & Good & Fair & Poor \\
\hline Sneezing & 100 & 80 & 13 & 7 \\
\hline Rhinorrhoea & 100 & 55 & 38 & 7 \\
\hline $\begin{array}{c}\text { Nasal } \\
\text { Obstruction }\end{array}$ & 90 & 55 & 35 & 0 \\
\hline $\begin{array}{c}\text { Ocular } \\
\text { Symptoms }\end{array}$ & 10 & - & 7 & 3 \\
\hline Nasal Irritation & 83 & 30 & 40 & 13 \\
\hline $\begin{array}{c}\text { Throat } \\
\text { Irritation }\end{array}$ & 70 & 20 & 30 & 20 \\
\hline Headache & 23 & 15 & 8 & - \\
\hline Others & 71 & 20 & 40 & 11 \\
\hline \multicolumn{5}{|c|}{ Table 2. Shows the Results of Symptomatic } \\
Relief of the Patient
\end{tabular}

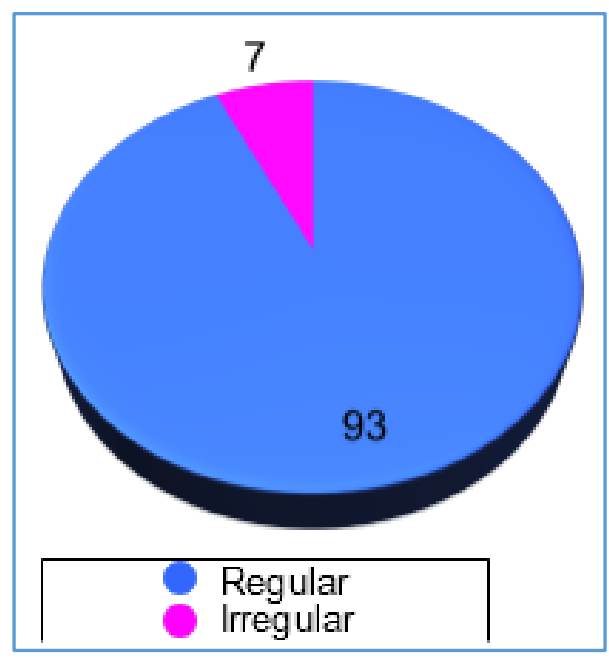

Figure 4. Follow-Up of Patients

\begin{tabular}{|c|c|c|}
\hline No. of Cases & Improved & Not Improved \\
\hline No. of Cases & 73 & 20 \\
\hline \multicolumn{2}{|c|}{ Table 3. Results showing Improvement } \\
\hline
\end{tabular}

\section{DISCUSSION}

Since allergic rhinitis is induced by specific allergens, it makes sense that avoiding those triggers would be an effective treatment. However, this is not always possible as in the case of pollens and for those with mixed allergic and nonallergic rhinitis, avoidance will not completely alleviate their symptoms. 5

Application of silver nitrate solution of different concentrations has been used in the treatment of allergic rhinitis and vasomotor rhinitis in the past. ${ }^{6} \mathrm{~A}$ new, simple and effective local treatment of allergic and vasomotor rhinitis is using 15 percent silver nitrate, bilateral chemical cautery of the anterior part of the nasal septum and inferior turbinates. ${ }^{7}$ This treatment has been given only to those persons who had sneezing as the presenting symptom. Not only is sneezing troublesome to the patient, but it also annoys his relations, friends and neighbours. The treatment consists of the bilateral application of 15 percent silver nitrate to the anterior part of the nasal septum and to the anterior portion of the inferior turbinates, once a week on one to five occasions. 15 percent silver nitrate is often applied in the pharynx to reduce its irritability. Silver nitrate produces a local astringent action by coagulating albumin. This action seems to reduce the sensitivity and excitability of the mucous membrane treated with silver nitrate. The anterior parts of the nasal septum and inferior turbinates appear to be the 'trigger zones' whose stimulation leads to sneezing and rhinorrhoea. Silver nitrate reduces the sensitivity and excitability of these 'trigger zones' and thus relief is obtained. Once the nasal allergy is controlled, spread to the lower respiratory tract is prevented. ${ }^{7}$

In the present study, an attempt has been made to prove that local application of $15 \%$ silver nitrate is a simple and effective treatment with negligible side effects. The old practice of reducing the irritability of the throat by painting it with dilute solutions of silver nitrate was the basis for this treatment.

In our study, 100 patients with allergic rhinitis were selected randomly. In our study, there is predominance of females (55\%) over males (45\%). Rates of prevalence of allergic rhinitis are similar for males and females and no racial or ethnic variations are reported. ${ }^{8}$ Symptoms of allergic rhinitis can begin at any age, but are most frequently first reported in adolescence or young adulthood. In our study, maximum patients were in the age group of 18 - 29 years.

In our study, all 100 patients presented with sneezing and nasal discharge. 90 out of 100 patients had nasal obstruction. Nasal irritation was present in $83 \%$ of cases. Headache and ocular symptoms were present in $23 \%$ and $10 \%$ respectively. Other symptoms like cough, itching and blocking of the ears were present in $71 \%$ of the cases. Similar predominance of sneezing and rhinorrhoea were observed in the other 2 studies. ${ }^{7,9}$ The treatment with $15 \%$ silver nitrate solution was effective in relieving rhinorrhoea with good relief in 55\% and fair in $38 \%$ of cases. Good relief from nasal obstruction was seen in $61 \%$ cases and fair in $39 \%$. Headache was relieved in $65 \%$ of cases. The best relief obtained was from sneezing with good relief in $80 \%$ and fair in $13 \%$ of cases.

Comparing our results with Bhargava's results shows that cases with complete or almost complete relief from sneezing were classified as having a 'good result.' Those with substantial reduction in sneezing were grouped under 'fair result.' A poor relief meant absence of relief or insignificant relief. The treatment was considered to be successful in $68.3 \%$ of cases with good relief recorded in $58.6 \%$ of cases and substantial relief was reported by $9.7 \%$. The results obtained in our study was comparatively better (78.49\%). We found 73 out of 93 cases improved after five applications giving a successful result of $78.49 \%$. These cases have been followed up for a period ranging from one to six months. Silver nitrate poisoning can lead to a high percentage of Methaemoglobin in the blood and pigmentation of the gums. ${ }^{7}$ 
In our study, no such tests were done as there were no complaints from patients. Complications related to the procedure were minimal. Most patients tolerated it well with a few side effects like burning sensation in nose along with transient rhinorrhoea, which settled in few hours' time. Other studies also reported minimal and well tolerated side effects.7,10 Local application of $15 \%$ silver nitrate have been found to be simple and effective for patients who accept the treatment readily. It can be applied in children over the age of 8 years and it is useful even in those patients who have been treated with corticosteroids locally or systemically. The two kinds of treatment can be complementary to each other for those patients who do not experience relief with one or other mode of therapy. From the above discussion, it is evident that local application of $15 \%$ silver nitrate is effective in the treatment of Allergic Rhinitis with successful result of 78 . $49 \%$ in our study with negligible side effects. Long-term results are awaited, and it is suggested that further studies are necessary regarding the number of applications, the interval between applications, the strength of the silver nitrate solution and the possible use of other chemical or physical agents for this mode of treatment.

The treatment by local application of $15 \%$ silver nitrate is easy and effective in relieving symptoms. The effect of treatment lasts for a longer time and cost effective. Patients readily accept the treatment and it can be easily repeated if symptoms recur. Side effects are negligible, and no premedication is required. No sophisticated equipment or surgery is required. It has a wide application, as the disease is very prevalent.

\section{CONCLUSION}

The treatment by local application of $15 \%$ silver nitrate is easy and effective in relieving symptoms. The effect of treatment lasts for a longer time and cost effective. Patients readily accept the treatment and it can be easily repeated if symptoms recur. Side effects are negligible, and no premedication is required. No sophisticated equipment or surgery is required. It has a wide application, as the disease is very prevalent.

\section{REFERENCES}

[1] Wallace DV, Dykewicz MS, Bernstein DI, et al. The diagnosis and management of rhinitis: an updated practice parameter. J Allergy Clin Immunol 2008;122(2 Suppl):S1-84.

[2] Van Cauwenberge P, Bachert C, Passalacqua G, et al. Consensus statement on the treatment of allergic rhinitis. European academy of allergology and clinical immunology. Allergy 2000;55(2):116-34.

[3] Benninger M, Farrar JR, Blaiss $M$, et al. Evaluating approved medications to treat allergic rhinitis in the United States: an evidence-based review of efficacy for nasal symptoms by class. Ann Allergy Asthma Immunol 2010;104(1):13-29.

[4] Nathan RA. The burden of allergic rhinitis. Allergy Asthma Proc 2007;28(1):3-9.

[5] Tran NP, Vickery J, Blaiss MS. Management of rhinitis: allergic and non-allergic. Allergy Asthma Immunol Res 2011;3(3):148-56.

[6] Aslam MJ, Aslam MA, Khan AS, et al. Treatment of nasal obstruction due to hypertrophic inferior turbinates with application of silver nitrate solution. Ann Pak Inst Med Sci 2009;5(4):201-5.

[7] Bhargava KB, Abhyankar US, Shah TM. Treatment of allergic and vasomotor rhinitis by the local application of silver nitrate. J Laryngol Otol 1980;94(9):1025-36.

[8] Hack W. Reflex Neurosis. In: Rhinology Scott Brown and illustrated history London. Butterworth, Oxford 1997;4(9):1-12.

[9] Al-Samarrae SM. Treatment of vasomotor rhinitis by the local application of silver nitrate. J Laryngol Otol 1991;105(4):285-7.

[10] Latif S, Aslam N. Treatment of allergic rhinitis by $25 \%$ silver nitrate cauterization. Proceeding Shaikh Zayed Postgrad Med Inst 2004;18(2):69-72. 